\title{
Cardioprotection against reperfusion injury is maximal with only two minutes of sevoflurane administration in rats
}

\author{
[La cardioprotection contre les lésions de reperfusion est maximale après deux \\ minutes seulement d'administration de sévoflurane chez des rats]
}

Detlef Obal MD, Horst Scharbatke, Holger Barthel MD, Benedikt Preckel MD DEAA, Jost Müllenheim MD DEAA, Wolfgang Schlack MD DEAA

\begin{abstract}
Purpose: Volatile anesthetics can protect the heart against reperfusion injury. When sevoflurane is given for the first 15 min of reperfusion, a concentration corresponding to one minimum alveolar concentration (MAC) provides a maximum protective effect. The present study addresses the question of how long sevoflurane has to be administered to achieve the best cardioprotection.
\end{abstract}

Methods: Chloralose anesthetized rats were subjected to a 25min occlusion of a major coronary artery, followed by 90 min of reperfusion. During the initial phase of reperfusion, an end-tidal concentration of 2.4 vol.\% of sevoflurane (I MAC) was given for two $(n=8)$, five $(n=8)$ or ten minutes $(n=7)$. Seven rats served as untreated controls. We measured left ventricular (LV) pressure, mean aortic pressure and infarct size (triphenyltetrazolium staining).

Results: Administration of sevoflurane for two minutes resulted in the greatest reduction of infarct size to 15\% (8-22 [mean (95\% confidence interval)] of the area at risk compared with controls [5 I $(47-55) \%, P<0.00 I$ l]. Five or ten minutes of sevoflurane administration reduced infarct size to 26 (I8-34) and 26 (I8-35) \% [P < $0.05]$, respectively. The cardiodepressant effect of sevoflurane varied with the duration of its administration: $\mathrm{LV} \mathrm{dP/dt}$ was reduced from $6332 \mathrm{mmHg} \cdot \mathrm{sec}^{-1}(577 \mathrm{I}-6894)$ during baseline to $421 \mathrm{I}$ $\mathrm{mmHg} \cdot \mathrm{sec}^{-1}$ (303I-539l), 38I I mmHg.sec ${ }^{-1}(208 \mathrm{l}-5540)$ and $3612 \mathrm{mmHg} \cdot \mathrm{sec}^{-1}$ (2864-4359) after two, five and ten minutes of reperfusion, respectively.

Conclusion: Administration of I MAC sevoflurane for the first two minutes of reperfusion effectively protects the heart against reperfusion injury in rats in vivo. A longer administration time had lesser cardioprotective effects in this experimental model.
Objectif : Les anesthésiques volatils peuvent protéger le cœur contre les lésions de reperfusion. Lorsque le sévoflurane est administré pendant les 15 premières minutes de la reperfusion, une concentration correspondant à une concentration alvéolaire minimale (CAM) fournit un effet protecteur maximal. Nous voulions déterminer le temps d'administration de sévoflurane nécessaire pour atteindre la meilleure cardioprotection.

Méthode : Des rats anesthésiés à la chloralose ont été soumis à 25 min d'occlusion d'une artère coronaire principale, suivie de 90 min de reperfusion. Pendant la phase initiale de reperfusion, une concentration télé-expiratoire de 2,4 vol.\% de sévoflurane (I CAM) a été donnée pendant deux $(n=8)$, cinq $(n=8)$ ou dix minutes $(n=7)$. Sept rats non traités ont servi de témoins. Nous avons mesuré la pression ventriculaire gauche (VG), la pression aortique moyenne et la taille de l'infarctus (coloration au triphényltétrazolium).

Résultats : L'administration de sévoflurane pendant deux minutes a donné la plus importante réduction de la taille de l'infarctus à $15 \%$ de l'aire à risque (8-22 [moyenne (intervalle de confiance de $95 \%)$ ], comparativement aux témoins [5I (47-55) \%, P < 0,00 I]. L'administration pendant 5 à 10 min a respectivement réduit l'infarctus à 26 (18-34) et à $26(18-35) \%[P<0,05]$. L'effet cardiodépresseur du sévoflurane a varié avec la durée de l'administration : la dP/dt du VG a été, respectivement, réduite de $6332 \mathrm{mmHg} \cdot \mathrm{sec}^{-1}$ (577I-6894), comme mesure de

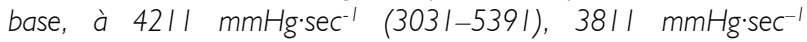
(2081-5540) et $3612 \mathrm{mmHg} \cdot \mathrm{sec}^{-1}$ (2864-4359) après deux, cinq et dix minutes de reperfusion.

Conclusion : L'administration de I CAM de sévoflurane pendant les deux premières minutes d'une reperfusion protège efficacement le cœur contre les lésions de reperfusion in vivo chez des rats. Une administration prolongée produit moins d'effets cardioprotecteurs chez ce modèle expérimental.

From the Klinik für Anaesthesiologie, Universitätsklinikum Düsseldorf, Germany. Address correspondence to: Professor Dr. Wolfgang Schlack, Klinik für Anaesthesiologie, Universitätsklinikum Düsseldorf, Postfach 1010 07, D-40001 Düsseldorf, Germany. Phone: 49-211-811-8669; Fax: 49-211-811-6253; E-mail: schlack@uni-duesseldorf.de Accepted for publication January 24, 2003.

Revision accepted July 2, 2003. 


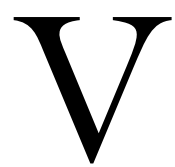

OLATILE anesthetics may provide cardioprotection by three different mechanisms: first, given and discontinued before ischemia they induce a preconditioninglike effect resulting in pronounced cardioprotection; second, given during ischemia, they have a small antiischemic effect; and third, given after ischemia during reperfusion, they provide strong cardioprotection against reperfusion injury. ${ }^{1}$ This protection against reperfusion injury was shown for sevoflurane after myocardial ischemia in vitro ${ }^{2,3}$ and in vivo. ${ }^{4}$ We have recently demonstrated that one minimum alveolar concentration (MAC) of sevoflurane significantly reduced myocardial reperfusion injury in rats. ${ }^{5}$ An increase of the anesthetic concentration above 1 MAC did not reduce reperfusion injury further. In most studies, drugs that offer protection against reperfusion injury were given for at least $15 \mathrm{~min}$ during reperfusion. From studies in isolated cardiomyocytes it is known that the protection can be achieved within the first few minutes of reperfusion. ${ }^{6,7}$ Therefore, we hypothesized that a shorter duration of administration of sevoflurane might also induce cardioprotection while, at the same time, limit its cardiovascular side effects. In the present study we investigated the effects of two, five and ten minutes administration of 1 MAC sevoflurane on infarct size after regional coronary artery occlusion in rats in vivo.

\section{Material and methods}

The study was performed in accordance with the regulations of the German Animal Protection Law and was approved by the District Government of Düsseldorf.

\section{Animal preparation}

The surgical procedures have been described in detail previously. ${ }^{5}$ In brief, chloralose-anesthetized Wistar rats [body weight 490 (477-503) g (mean (95\% confidence interval)] were intubated and ventilated (RhemaLabortechnik, Typ $10 \mathrm{~mL}$, Class 34931, Germany) with a tidal volume of $5 \mathrm{~mL}$ at 60 breaths $\mathrm{min}^{-1}$. The rats were instrumented for measurement of mean aortic pressure (MAP), left ventricular (LV) pressure (LVP) and cardiac output $(\mathrm{CO})$. A ligature snare was looped around a major coronary artery for later occlusion. The coronary anatomy of rats is highly variable and does not follow the classical scheme with only two main branches of the left coronary artery. The major branch of the left coronary artery serving the left anterior wall was used for ischemia and reperfusion.

\section{Experimental protocol}

Hemodynamic variables were recorded after a 15 -min stabilization period. Regional myocardial ischemia was induced by tightening the snare around the prepared coronary artery. Myocardial ischemia was verified by the appearance of epicardial cyanosis and changes in surface electrocardiogram. After 25 min of occlusion, the snare occluder was released and successful reperfusion was evidenced by the disappearance of epicardial cyanosis. At the beginning of reperfusion, the rats received sevoflurane in an end-tidal concentration of 2.4 vol.\% (1 MAC in rats $)^{8}$ for two $(n=8)$, five $(n=$ $8)$ or ten $(n=7)$ minutes. By using a high inspiratory flow of $12 \mathrm{~L} \cdot \mathrm{min}^{-1}$, stable sevoflurane concentrations could be achieved within $15 \mathrm{sec}$ as evidenced by rapid changes in hemodynamics already during the first seconds of sevoflurane administration. Sevoflurane concentration was measured in the expiratory gas (Datex Capnomac Ultima, Division of Instrumentarium Corp., Helsinki, Finland) at a sampling rate of 200 $\mathrm{mL} \cdot \mathrm{min}^{-1}$. Control rats $(n=7)$ did not receive sevoflurane during reperfusion.

\section{Measurement of infarct size}

After 90 min of reperfusion, the hearts were quickly excised and infarct size was measured as described previously. ${ }^{5}$ Hearts were perfused on a modified Langendorff apparatus with normal saline at 80 $\mathrm{mmHg}$ perfusion pressure to wash out any remaining blood. The coronary artery was then reoccluded and $5-10 \mathrm{~mL}$ of $0.2 \%$ Evans Blue dye in $1 \%$ dextran was infused via the aortic root into the coronary system. This maneuver identifies the area at risk as unstained. The heart was then frozen, cut into thin slices $(1 \mathrm{~mm})$ and incubated $\left(15 \mathrm{~min}, 37^{\circ} \mathrm{C}\right)$ in buffered $1 \%$ triphenyltetrazolium chloride to identify viable myocardium as red stained while necrotic tissue remains pale gray. The area at risk and the infarcted area were determined by planimetry by one observer blinded to the study group.

\section{Data analysis}

LVP, its first derivative $\mathrm{dP} / \mathrm{dt}$, aortic pressure and $\mathrm{CO}$ were recorded continuously on a polygraph (Hellige 120710 94, Freiburg, Germany) and were digitized at different time points using an analogue-to-digital converter (Data Translation, Marlboro, MA, USA) at a sampling rate of $500 \mathrm{~Hz}$ and processed later on a personal computer.

\section{Hemodynamic variables}

Global systolic function was measured in terms of LV peak systolic pressure (LVPSP) and the maximum rate 
of pressure increase (dP/dtmax). Global LV end-systole was defined as the point of minimum $\mathrm{dP} / \mathrm{dt}$ and LV end-diastole as the beginning of the sharp upslope of the $\mathrm{LV} \mathrm{dP} / \mathrm{dt}$ tracing. Systemic vascular resistance (SVR) was calculated from MAP and CO, assuming a right atrial pressure of $0 \mathrm{mmHg}$ in the open-chest preparation.

\section{Statistical analysis}

Results are expressed as means and 95\% confidence interval. Statistical analysis of the hemodynamic variables was performed by a two-way analysis of variance (ANOVA) for time and treatment (duration of sevoflurane administration) effects. Time effects (changes from baseline value) during the experiments were analyzed by using Dunnett's post-hoc test. A repeated measure design was used for the time factor. If an overall significance between groups was found, comparison was made for each time using one-way ANOVA followed by Tukey's post-hoc test where appropriate. For statistical analysis of the differences between the infarct size, one-way ANOVA followed by Tukey's post-hoc test was used.

\section{Results}

Thirty-six rats were used. Six rats died from ventricular fibrillation during coronary artery occlusion. In the remaining 30 animals, complete data sets were obtained.

\section{Hemodynamic function}

At the beginning of the experiments there were no differences in hemodynamics observed between groups (data are summarized in Table I - available at www.cjajca.org as additional material - and Figure 1). Occlusion of the coronary artery resulted in a reduction of LVPSP and SVR to 91 (84-98) \% and $89(80-99) \%$ of baseline values, respectively, similar in all groups (data at $24 \mathrm{~min}$ of ischemia, no significant changes from baseline in any group). Simultaneously, dP/dtmax [95 (86-104)\%] and CO [94 (90-99) \%] were only minimally affected. LV end-diastolic pressure (LVEDP) increased to 185 (156-213) \% of baseline.

During reperfusion, no changes from ischemic values were observed in controls, except for a further reduction in SVR to 61 (24-97) \% of baseline and an increase of LVEDP to 314 (104-525) \% of baseline $(P$ $<0.05$, values at $90 \mathrm{~min}$ of reperfusion). Administration of sevoflurane for two minutes reduced LVPSP to 75 (61-89) \% of baseline ( $P=n s)$. This reduction was similar after five [76 (58-94) \%] and after ten minutes of sevoflurane administration [69 (56-82) \% of baseline, at the end of each administration period]. Depending on
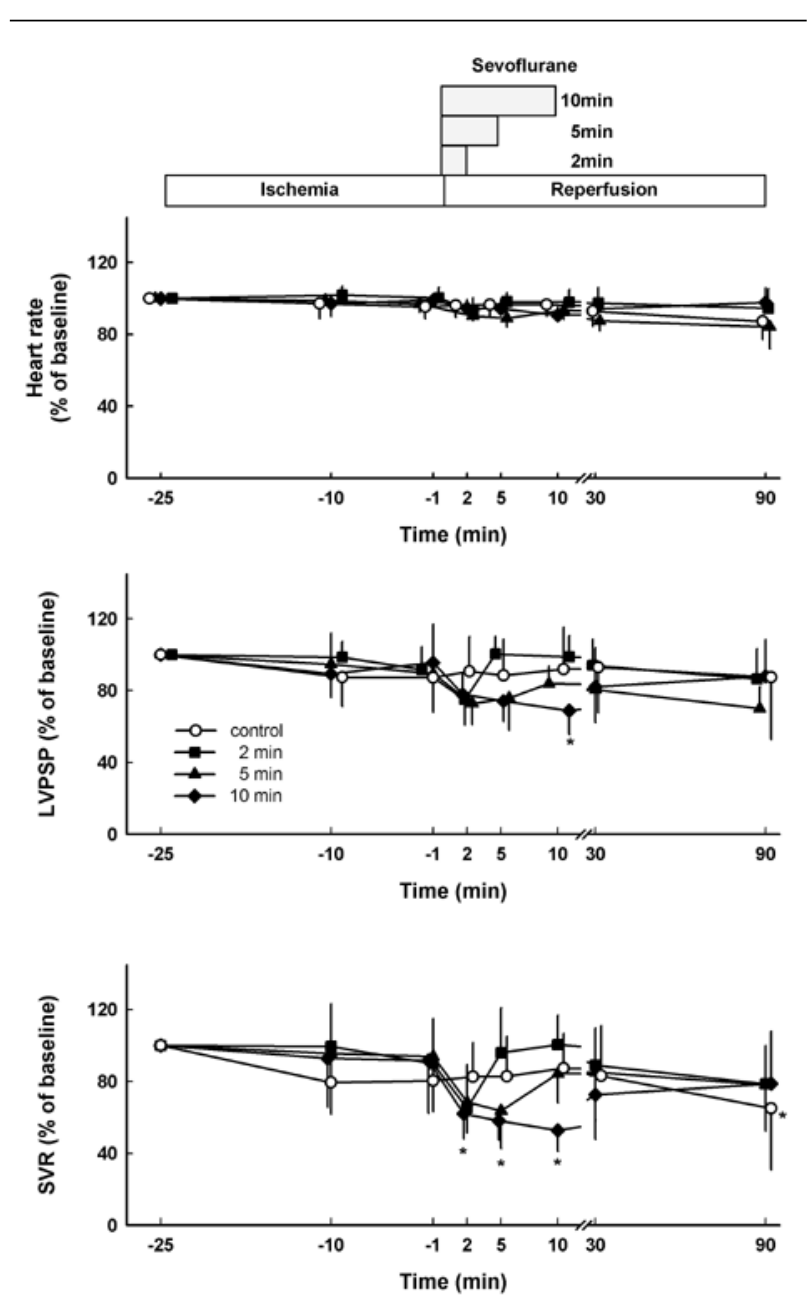

FIGURE 1 Line plot showing the time course of heart rate (HR), left ventricular peak systolic pressure (LVPSP) and systemic vascular resistance (SVR) during the experiments. Percent data of baseline are means ( $95 \%$ confidence interval). * Indicates differences from baseline on raw data

the duration of sevoflurane inhalation, $\mathrm{dP} / \mathrm{dtmin}$ was reduced to $46(31-62) \%(P<0.05$, Table I - CJA online) and SVR to 53 (41-64) \% (Figure 1), while CO remained unchanged.

\section{Infarct size}

Mean LV dry weight was 0.17 (0.16-0.18) g with no differences between groups (data for the individual groups are given in Table II). The ischemic-reperfused area (area at risk) constituted $34(28-39) \%$ of the LV. In controls, infarct size was $51(47-55) \%$ of the area at risk (Figure 2). Two minutes of sevoflurane admin- 


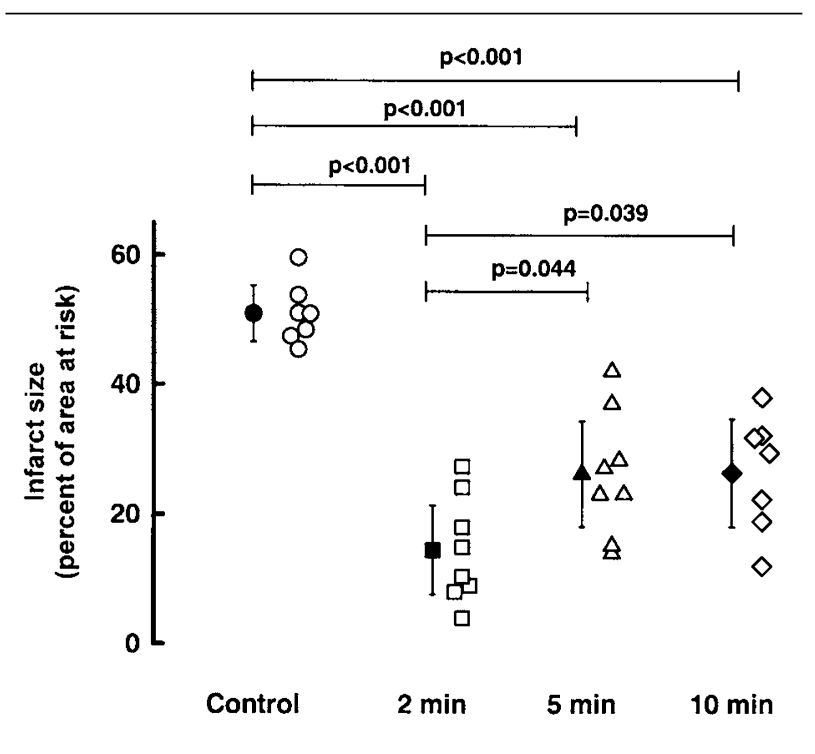

FIGURE 2 Infarct size expressed as percent of the area at risk of the control group and the groups receiving sevoflurane for two $(2$ $\mathrm{min})$, five $(5 \mathrm{~min})$ or ten $(10 \mathrm{~min})$ minutes of reperfusion. Open symbols represent single data points, filled symbols are means and $95 \%$ confidence interval.

TABLE II Left ventricular weight and area at risk size in the control group and the groups receiving I MAC of sevoflurane for two, five or ten minutes at the start of reperfusion.

\begin{tabular}{lll}
\hline Group & Left ventricle (g) & Area at risk (\% of left ventricle) \\
\hline Control & $0.15(0.13-0.16)$ & $0.39(0.25-0.52)$ \\
$2 \mathrm{~min}$ & $0.18(0.16-0.20)$ & $0.35(0.23-0.47)$ \\
$5 \mathrm{~min}$ & $0.18(0.15-0.21)$ & $0.29(0.20-0.38)$ \\
$10 \mathrm{~min}$ & $0.17(0.12-0.23)$ & $0.33(0.15-0.51)$ \\
\hline
\end{tabular}

Data are means $(95 \%$ confidence interval $) . \mathrm{MAC}=$ minimum alveolar concentration.

istration reduced infarct size to $15(8-22) \%$ of the area at risk $(P<0.001$ vs control $)$. Five minutes [26 $(18-34) \%$ ] or ten minutes [26 (18-35) \%] administration of 1 MAC sevoflurane also reduced infarct size (both $P<0.001 v s$ control), but less than in the twominute group (both $P<0.05$ ).

\section{Discussion}

After myocardial ischemia, lethal reperfusion injury characterizes a situation in which the myocardium loses viability by mechanisms which are triggered by the restoration of oxygen and substrate supply. ${ }^{9}$ Volatile anesthetics offer specific protection against myocardial reperfusion injury. ${ }^{2,10-12}$ Sevoflurane in a concentration corresponding to 1.5 MAC reduced creatine kinase release and improved myocardial function after global ischemia in isolated rat hearts. ${ }^{2}$ Sevoflurane (1 MAC) reduced infarct size after regional ischemia in rabbits in vivo. ${ }^{4}$ Recent data demonstrated that 1 MAC sevoflurane during the first $15 \mathrm{~min}$ of reperfusion was sufficient to reduce infarct size and a higher concentration (1.5 or 2.0 MAC) offered no further protection. ${ }^{5}$ During reperfusion, the majority of changes in intracellular homeostasis occur rapidly during the first minutes, and, therefore it is likely that administration of sevoflurane for a shorter period than $15 \mathrm{~min}$ may protect the heart against reperfusion injury.

The present data show that administration of 1 MAC sevoflurane for two minutes at the beginning of reperfusion is effective in protecting the heart against reperfusion injury. A longer administration time was also protective, but the reduction in infarct size was less pronounced than after a two-minutes period of sevoflurane administration.

Experimental models of acute myocardial infarction show that the attenuation of reperfusion injury by different drugs depends on blood concentrations and, presumably, the concentration of the respective drug in the myocardium at the start of reperfusion. ${ }^{13,14}$ Sevoflurane has a low blood-gas partition coefficient of 0.59 , which is associated with a rapid wash-in and wash-out rate. ${ }^{15}$ In our study, 15 to $20 \mathrm{sec}$ after starting sevoflurane inhalation, a reduction of $\mathrm{dP} / \mathrm{dt}$ was observed. This myocardial depressant effect indicates that even during this short period of administration, a substantial amount of sevoflurane was present in the myocardium. However, the tissue concentrations in the heart were not measured in the present study.

The underlying mechanism responsible for cytolysis of hypoxic-reoxygenated cells was described as the 'oxygen paradox'. ${ }^{16}$ Re-supply of adenosine triphosphate after reactivation of oxidative phosphorylation causes uncontrolled calcium release from the sarcoplasmic reticulum, leading to cellular contractions when the calcium overload exceeds the capacity of the sarcoplasmic reticulum. In vitro findings show that the critical time period for sarcoplasmic reticulum calcium oscillations are the first two to five minutes of reoxygenation. ${ }^{17}$ When ryanodine is used to block calcium release from the sarcoplasmic reticulum, these oscillations vanish. ${ }^{18}$ Administration of a volatile anesthetic during reoxygenation can prevent these oscillations and reduce cellular hypercontracture. ${ }^{7}$ This might be one possible mechanism for the reduction of infarct size observed in the present study. 
It is remarkable and difficult to explain that a longer administration of sevoflurane (five or ten minutes) resulted in a greater infarct size compared with only two minutes of sevoflurane administration. The number of animals in our study is small and there might be the possibility, despite a significant difference with the conservative Tukey's test, that the effect in the two minutes group could still be due to chance. However, there is no advantage of longer sevoflurane administration. The difference in hemodynamics between the five and ten minutes groups and the twominutes group consisted of a more pronounced and longer lasting cardiovascular depression during sevoflurane administration. It has been shown that a (mechanical) reduction of myocardial afterload ${ }^{19}$ and a staged reperfusion ${ }^{20}$ reduce reperfusion injury. In contrast, there is some evidence that the cardioprotection offered by volatile anesthetics is independent of simultaneous changes in myocardial contractility and loading conditions. The protective effects of the volatile anesthetic halothane were independent from its cardiodepressant effect and were unchanged if the cardiodepression was counterbalanced by simultaneous noradrenaline infusion. ${ }^{11}$ In isolated rat hearts ${ }^{10}$ and in the rabbit in vivo, different volatile anesthetics (enflurane, sevoflurane, desflurane $)^{4}$ have different cardiodepressant but similar cardioprotective effects. In addition to direct effects on the myocardium and on hemodynamics, interaction with leukocyte activation, capillary plugging by leukocytes, free radical production and changes in regional myocardial blood flow might have influenced the protection against myocardial damage. ${ }^{21}$ Therefore, during the later stages of reperfusion, the no-reflow phenomenon of plugged capillaries may play an important role. ${ }^{22,23}$ The reduction of coronary perfusion pressure concomitant with the longer administration of sevoflurane may have contributed to the partial reversal of the cardioprotective effect observed in this experimental model.

It is difficult to extrapolate experimental data to the clinical scenario. However, there is some evidence that volatile anesthetics offer protective effects against myocardial ischemia in patients undergoing coronary artery bypass surgery. ${ }^{24,25} \mathrm{Up}$ to now, no data are available concerning protective effects of volatile anesthetics in non-cardiac surgery. The incidence of surgical procedures in elderly patients increases, concomitant with a high prevalence of coronary heart disease. ${ }^{26}$ In these patients with high risk for perioperative cardiac events, myocardial infarction occurs in $6.6 \%$ even after non-cardiac surgery ${ }^{27}$ and it is likely that volatile anesthetics offer beneficial effects in clinical ischemia-reperfusion situations in these patients.
In summary, we demonstrated that 1 MAC of sevoflurane given for only two minutes of reperfusion provides an optimum protective effect against reperfusion injury in the rat heart in vivo.

\section{References}

1 Kato R, Foex P. Myocardial protection by anesthetic agents against ischemia-reperfusion injury: an update for anesthesiologists. Can J Anesth 2002; 49: 777-91.

2 Schlack W, Preckel B, Stunneck D, Thämer V. Effects of halothane, enflurane, isoflurane, sevoflurane and desflurane on myocardial reperfusion injury in the isolated rat heart. Br J Anaesth 1998; 81: 913-9.

3 Preckel B, Thämer V, Schlack W. Beneficial effects of sevoflurane and desflurane against myocardial reperfusion injury after cardioplegic arrest. Can J Anesth 1999; 46: 1076-81.

4 Preckel B, Schlack W, Comfere T, Obal D, Barthel H, Thämer $V$. Effects of enflurane, isoflurane, sevoflurane and desflurane on reperfusion injury after regional myocardial ischaemia in the rabbit heart in vivo. $\mathrm{Br} \mathrm{J}$ Anaesth 1998; 81: 905-12.

5 Obal D, Preckel B, Scharbatke H, et al. One MAC of sevoflurane provides protection against reperfusion injury in the rat heart in vivo. Br J Anaesth 2001; 87: 905-11.

6 Siegmund B, Klietz T, Schwartz P, Piper HM. Temporary contractile blockade prevents hypercontracture in anoxic-reoxygenated cardiomyocytes. Am J Physiol 1991; 260: H426-35.

7 Siegmund B, Schlack W, Ladilov YV, Balser C, Piper $H M$. Halothane protects cardiomyocytes against reoxygenation-induced hypercontracture. Circulation 1997; 96: 4372-9.

8 Conzen PF, Vollmar B, Habazettl H, Frink EJ, Peter K, Messmer $K$. Systemic and regional hemodynamics of isoflurane and sevoflurane in rats. Anesth Analg 1992; 74: 79-88.

9 Jennings $R B$, Yellon DM. Reperfusion injury: definitions and historical background. In: Yellon DM, Jennings RB (Eds.). Myocardial Protection: The Pathophysiology of Reperfusion and Reperfusion Injury. New York: Raven Press; 1992: 1-11.

10 Schlack W, Hollmann M, Stunneck J, Thämer V. Effect of halothane on myocardial reoxygenation injury in the isolated rat heart. Br J Anaesth 1996; 76: 860-7.

11 Schlack W, Preckel B, Barthel H, Obal D, Thämer V. Halothane reduces reperfusion injury after regional ischaemia in the rabbit heart in vivo. Br J Anaesth 1997; 79: 88-96.

12 Ebel D, Preckel B, You A, Mullenheim J, Schlack W, Thämer V. Cardioprotection by sevoflurane against reperfusion injury after cardioplegic arrest in the rat is independent of three types of cardioplegia. $\mathrm{Br} \mathrm{J}$ 
Anaesth 2002; 88: 828-35.

13 Theroux $P$. Myocardial cell protection. A challenging time for action and a challenging time for clinical research (Editorial). Circulation 2000; 101: 2874-6.

14 Horwitz LD, Kong $\Upsilon$, Robertson AD. Timing of treatment for myocardial reperfusion injury. J Cardiovasc Pharmacol 1999; 33: 19-29.

15 Kazama T, Ikeda K. Comparison of MAC and the rate of rise of alveolar concentration of sevoflurane with halothane and isoflurane in the dog. Anesthesiology 1988; 68: 435-7.

16 Hearse DJ, Humphrey SM, Chain EB. Abrupt reoxygenation of the anoxic potassium-arrested perfused rat heart: a study of myocardial enzyme release. J Mol Cell Cardiol 1973; 5: 395-407.

17 Ladilov YV, Siegmund B, Piper HM. Protection of reoxygenated cardiomyocytes against hypercontracture by inhibition of $\mathrm{Na}^{+} / \mathrm{H}^{+}$exchange. Am J Physiol 1995; 268: H1531-9.

18 Siegmund B, Zude R, Piper HM. Recovery of anoxicreoxygenated cardiomyocytes from severe $\mathrm{Ca}^{2+}$ overload. Am J Physiol 1992; 263: H1262-9.

19 Shell WE, Sobel BE. Protection of jeopardized ischemic myocardium by reduction of ventricular afterload. $\mathrm{N}$ Engl J Med 1974; 291: 481-6.

20 Okamoto F, Allen BS, Buckberg GD, Bugyi H, Leaf J. Studies of controlled reperfusion after ischemia. XIV. Reperfusion conditions: importance of ensuring gentle versus sudden reperfusion during relief of coronary occlusion. J Thorac Cardiovasc Surg 1986; 92: 613-20.

21 Ambrosio G, Weisman HF, Mannisi JA, Becker LC. Progressive impairment of regional myocardial perfusion after initial restoration of postischemic blood flow. Circulation 1989; 80: 1846-61.

22 Rezkalla SH, Kloner RA. No-reflow phenomenon. Circulation 2002; 105: 656-62.

23 Camilleri JP, Joseph D, Fabiani JN, et al. Microcirculatory changes following early reperfusion in experimental myocardial infarction. Virchows Arch A Pathol Anat Histol 1976; 369: 315-33.

24 Belhomme D, Peynet J, Louzy M, Launay JM, Kitakaze $M$, Menasche $P$. Evidence for preconditioning by isoflurane in coronary artery bypass graft surgery. Circulation 1999; 100(suppl II): II340-4.

25 Haroun-Bizri S, Khoury SS, Chehab IR, Kassas CM, Baraka $A$. Does isoflurane optimize myocardial protection during cardiopulmonary bypass? J Cardiothorac Vasc Anesth 2001; 15: 418-21.

26 Mangano DT. Perioperative cardiac morbidity. Anesthesiology 1990; 72: 153-84.

27 Badner NH, Knill RL, Brown JE, Novick TV, Gelb AW. Myocardial infarction after noncardiac surgery. Anesthesiology 1998; 88: 572-8. 